\title{
Transparency in the Age of Scholarly Analytics
}

\author{
Mardy T. Eimers, Vice Provost for Institutional Research \& Quality \\ Improvement, University of Missouri
}

$\mathrm{T}$

There is a call for organizations of all types to be more transparent with the information they share externally, as well as internally. This is especially true in higher education, particularly public higher education. Constituencies want to know how their tax-generated state appropriations are spent and whether they are getting their "money's worth." How productive have your faculty been in their scholarly and creative pursuits? Have these research endeavors contributed to the well-being of the state, the nation, the world? Are students moving through the pipeline efficiently? Are students graduating and securing good jobs? These questions are at the forefront of the transparency movement in higher education. At the same time, transparency is important within the academy. Faculty and staff want access to the same information used by the key decision-makers, and they desire to understand the rationale behind the key decisions that will affect them directly.

In this paper, I focus partly on a single institution and its challenges with determining what information is most appropriate to cascade down and across the organization. Our university, which I'll refer to as Rivers University (RU), is a research university in the Midwest with approximately $50 \mathrm{PhD}$ programs. At RU we have slowly integrated the scholarly output data from Academic Analytics into their Academic Review Process and are looking for additional ways to share the data with faculty, chairs, deans, and other members of the university community.

Transparency and its basic Tenets

An examination of several articles from scholarly journals, as well as the popular press, finds little agreement on how transparency is defined. "Transparency has many different meanings" according to Bennis, Goleman and O'Toole
(2008), who authored a book on transparency. One relatively comprehensive definition is by Transparency International (2013): “Transparency is a characteristic of governments, companies, organizations and individuals that are open in the clear disclosure of information, rules, plans, processes, actions" (p. 1). This definition suggests that transparency should exist in a wide variety of institutions, both for profit and not-for-profit, and that these entities and individuals should be transparent with different kinds of information regarding how the entity shares internally and externally. Transparency relies significantly on information flow; which, according to Bennis, Goleman and O'Toole "...simply means that critical information gets to the right person at the right time and for the right reasons" ( $\mathrm{p}$. $4)$. Of course, this is an easy concept to 
understand in theory but a much more difficult concept to practice. Judgment certainly comes into play particularly when actually determining the right person, the right time, and the right reasons.

\section{Different types of Transparency}

An organization can be transparent in different ways with different constituencies. At its most basic level, an organization can be transparent in how they share data and information. In some cases, being transparent may mean providing a data set that can be analyzed and summarized by the parties that receive it. In this way, the receiver has the flexibility to analyze the data him or herself, and also understand the assumptions often build into summarized data. In other cases, it might mean providing a table or diagram where the data have already been summarized in a meaningful way. This may be the strong preference of those who do not have the skills or the time to summarize the data themselves. Much of the ability to be truly transparent depends on the audience's ability to understand and interpret the data provided. Organizational leaders can also be transparent by sharing actions, processes, and/or decisions. Sharing the rationale behind the decision or actions can be equally if not more important.

Transparency can also be categorized in terms of internal transparency and external transparency. Internal transparency refers to the information that flows through the organization. The information flowing from the organization to parties outside of the organization is coined external transparency. In this paper, I focus primarily on the decisions that surround sharing data internal to the organization. As a public institution, there is certainly less of a distinction between internal and external transparency. That is, data and information that are shared internally-albeit selectively, at a public university-are open to a wider audience through Sunshine requests and similar requests.

One other categorization of transparency is vertical transparency versus horizontal transparency. Vertical transparency is what is shared up and down the organization. For instance, vertical transparency would be when the chancellor shares information with the provost, the provost shares the data with deans, and deans pass the information on to the chairs, and so forth. How data are shared across the organization is an example of horizontal transparency. With Academic Analytics data, what information might be shared among all of the academic deans? All department chairs? Is it important that the department chairs know where their program ranks nationally in contrast to how the other RU departments rank?

\section{Insights from the Literature}

Numerous studies have been completed on the topic of organizational transparency. There have been recent studies that have identified the advantages and risks associated with being transparent (e.g., Bennis, Goleman, and O'Toole, 2008); different types of transparency (e.g., Nicolaou, 2010); a framework for identifying positive frames or categories of transparency (e.g., Wehmeier and Raaz, 2012), and even some publications that have suggested principles of transparency (Noveck, 2013). 
One of the most interesting studies was conducted by Wehmeier and Raaz (2012). The authors scanned the literature from 2000 through 2010 and identified 105 journal articles published on transparency. Most of these articles were in business, public relations, sociology, communications, and information technology. Specifically, over a one-half were in business, nearly a one-third in public relations, and the remainder scattered among the aforementioned disciplines. The authors concluded that a significant proportion of the articles had a positive connotation, $65 \%$ to be exact, with another $23 \%$ to have a neutral connotation toward transparency. None of the articles purported an exclusively negative connotation of transparency, although a handful ( 3 articles) reported both the positive and negative connotations of being transparent. The authors agreed with Beatele and Seidenglanz (2008) that particularly in public relations, "transparency is often seen as a precondition for trust, legitimacy, and reputation" (p. 338). Surprisingly, only a few authors challenged conventional wisdom, such as the notion that "transparency helps all the time" or that "transparency is a precondition of trust." Wehmeier and Raaz concluded: "Therefore, at present, most academics might view transparency as a solution to the growing criticism of business in society and do not focus on the problematic aspects of transparency" (p. 346). Certainly more transparent actions have been called for in higher education. Legislators and public officials, parents and students, and a host of others want to know how public higher education institutions are doing in terms of graduation rates, retention rates, assessment exams, employment opportunities, the true cost of educating a student, and so forth and so on.

The same is true within the academy. Faculty members, department chairs, directors, and even deans want to understand the data and information behind the planning, policy-setting, and decisions. Honoring the time-tested cornerstone of shared governance, between faculty and administrators, is more important today than it has ever been. That said, as the robustness of scholarly academic tools and data become more complete and sophisticated, no wonder provosts and senior leaders are finding it difficult to openly share these data without setting some parameters of use and principles of transparency.

\section{Analytical data about Scholarly Productivity}

Tremendous progress has been made in assembling quality scholarly data and building web interfaces to capture and use these data in planning and decision-making. One such company is Academic Analytics, Inc., a company that assembles scholarly output data at the faculty member level, combines these data by PhD program (e.g., Biological Sciences, History, etc.), and compared your institution's PhD program output with the output of other PhD programs in the same discipline. According to Academic Analytics, Inc., the data are scrubbed and checked and validated for each faculty member, a time consuming but critical step in the process. Institutions who subscribe to Academic Analytics, Inc. can then better understand the strengths and weaknesses of their PhD programs in 
contrast to $\mathrm{PhD}$ programs across the country. These are powerful data that have been talked about for years in higher education circles but never been available until the past decade.

Rivers University has subscribed to Academic Analytics for five years. We use the data almost exclusively in the academic program assessment process (e.g., academic program review, etc.) by championing "continuous improvement" in our academic assessment process. That is, we want department and program chairs to use the Academic Analytics data for their own purposes in an effort to make their PhD programs more competitive among peers. In the past, we have provided the provost, the dean, and the department chairs a paper and electronic version of their scholarly output in contract to their PhD program peers. To date, almost all of the data are in summary form.
But going forward things will change. RU has since subscribed to a module offered by Academic Analytics that displays "individual faculty scholarly outputs." This module enables analysts - and potentially the provost, deans, academic chairs - to look at the individual outputs of each faculty member sideby-side in the respective $\mathrm{PhD}$ program. This level of detail, albeit very useful, has been one of the factors that has given pause and careful consideration to exactly how these data are shared across campus and how best to determine who has access to specific data. Because detailed scholarly productivity information is now available, critical questions have arisen:

1. What data do you share?

2. With whom do you share the data?

3. When do you share the data?

4. In what format with how much flexibility?

\section{Chart 1: Example of PhD Program A Radar}

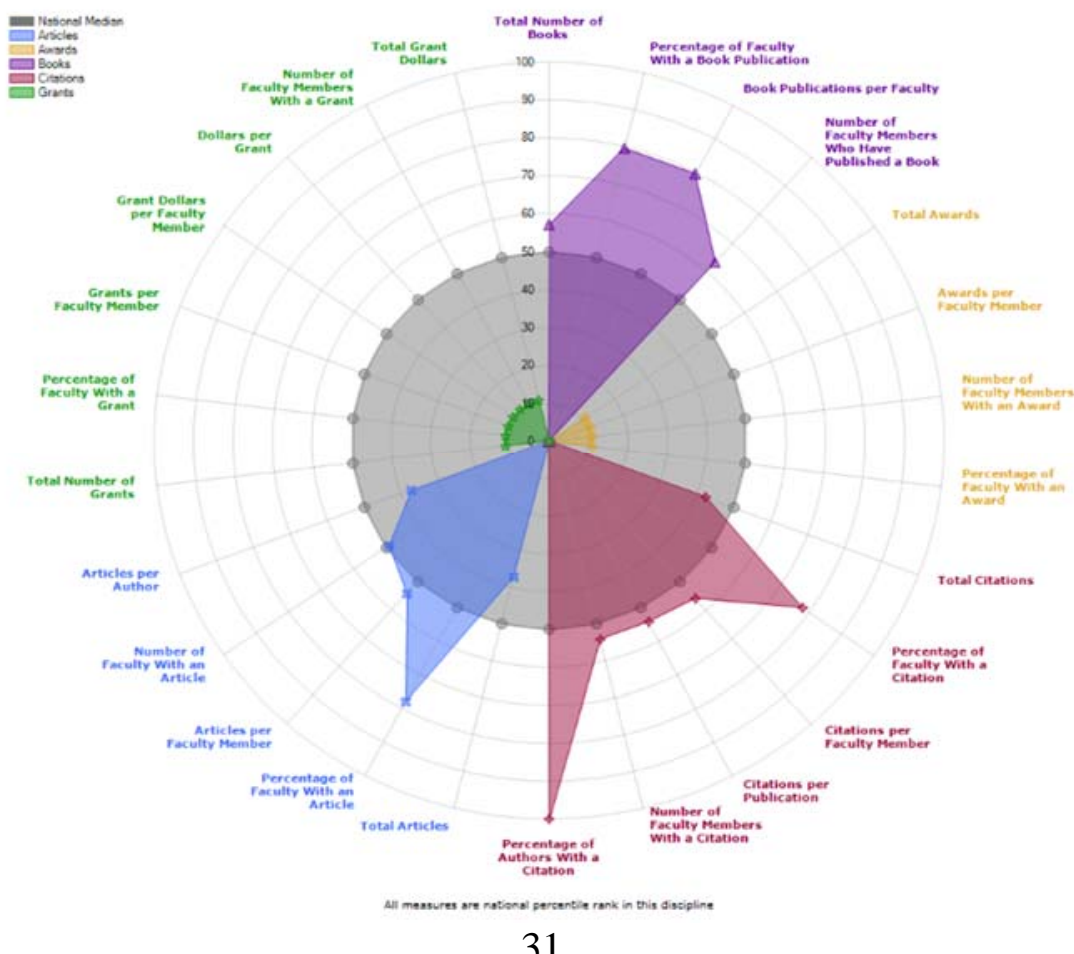


At Rivers University, as an example, what might be the implications of sharing Academic Analytics data with department chairs and faculty? Exactly what data do you share? Do you enable all chairs to see all other PhD program results? Do you share the national rankings for each $\mathrm{PhD}$ program so as to allow graduate students to take a closer look? Do you enable department chairs the full functionality of Academic Analytics website, including the ability to adjust weights for computing the Faculty Scholarly Productivity Index, or determine specific peer or aspirant departments for comparative purposes? The subsequent charts and tables provide examples and address many of these concerns.
Let's examine a handful of diagrams and charts provided by Academic Analytics. As you look at the information, think about whom within the university should have access to this information. Chart 1 displays how PhD Program A fares on several output factors when compared to like $\mathrm{PhD}$ programs in the same discipline. The grey circle is the $50^{\text {th }}$ percentile in the discipline.

In Chart 2, Academic Analytics takes all faculty members in all $\mathrm{PhD}$ programs in a given discipline (across the United States), ranks these faculty members in terms of scholarly outputs, and then places them in a quintile. The averages for each quintile are reflected in the table. The bar chart at the bottom of Chart 2

\section{Chart 2: Example of PhD Program P Quintile Analysis}

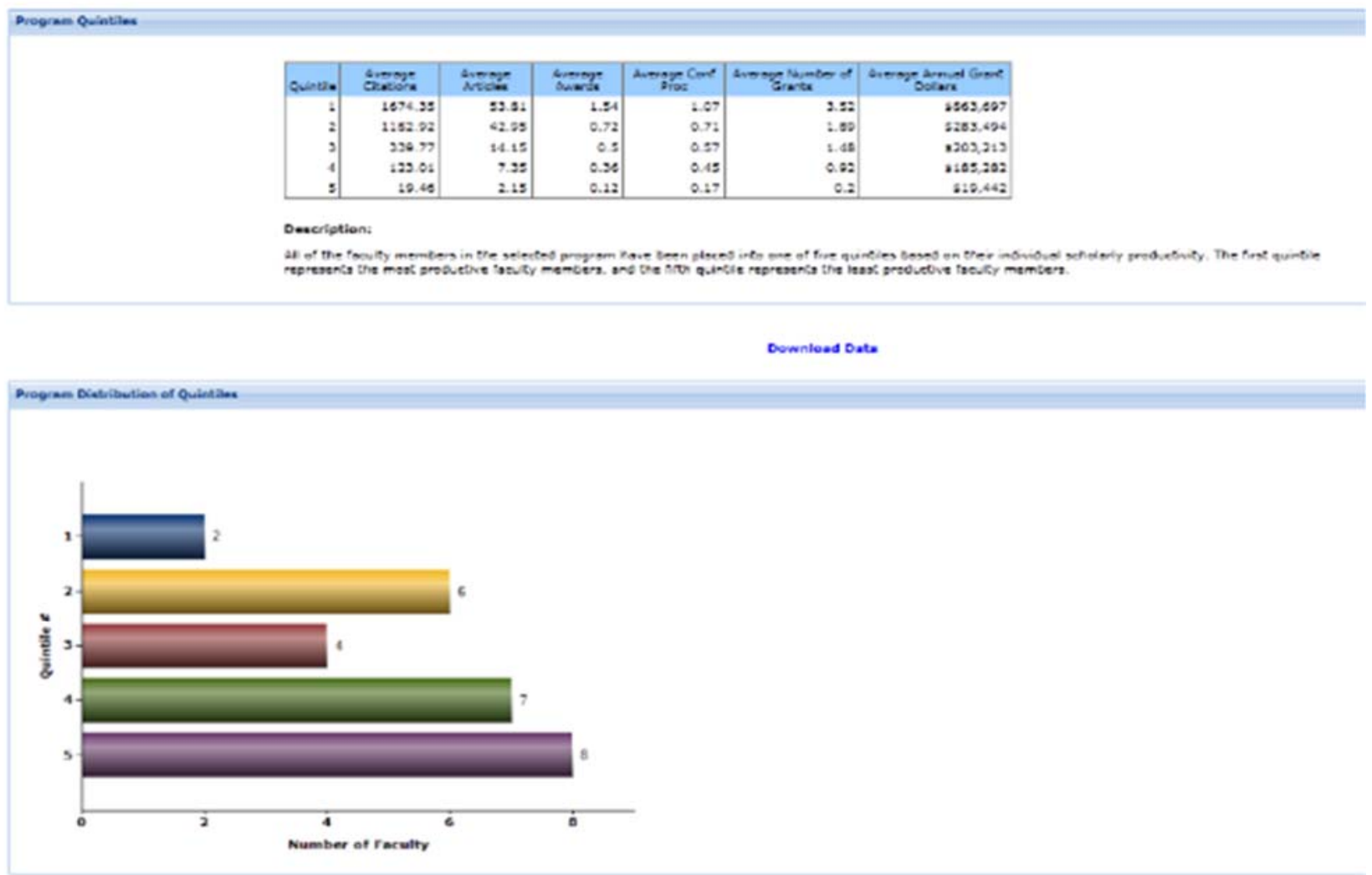


Chart 3: Example of PhD Program X Faculty Counts Summary

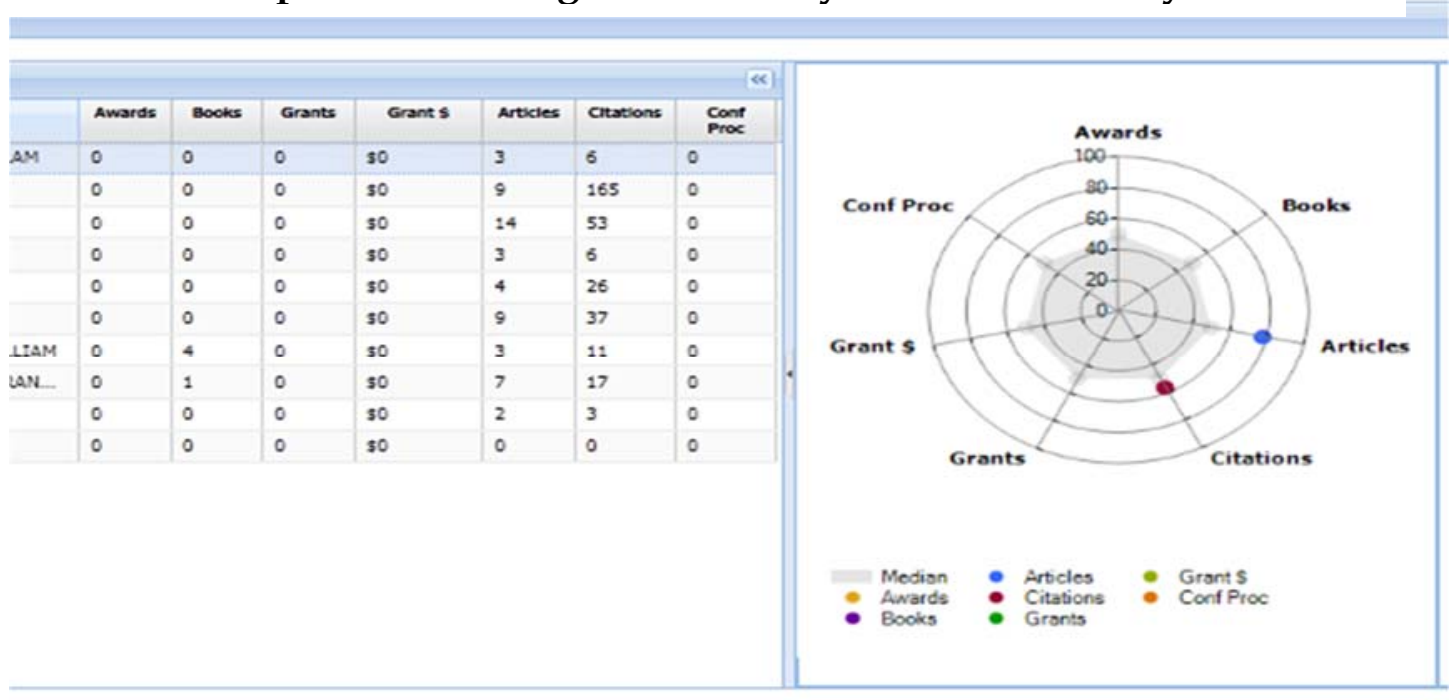

show where the institution's faculty fall in each quintile. For instance, PhD Program $\mathrm{P}$ has two faculty members in the top quintile, six faculty members in the second quintile, and so forth.

Chart 3 shows that scholarly productivity of each faculty member by name in
PhD Program $X$ over a 5 to 7 year period. In this example, the actual names of the faculty members have been removed but are represented by each row. For example, the first row indicates that this faculty member published 3 articles and had 6 citations from those articles. He or she

\section{Chart 4: Comparing PhD Programs at Rivers University}

Downioad Data Z. Switch To Chart View
AA Taxonomy (e Programs)
or numerically


did not receive any faculty awards, publish any books, nor secure any grants during this period. The "target" on the right displays this faculty member's output (denoted by the shaded row) and how he/she fits (red dot; blue dot) relative to peers in the sub-discipline.

Chart 4 provides an example of where PhD programs at RU rank in contrast to other $\mathrm{PhD}$ programs in their respective discipline. The FSPI (Faculty Scholarly Productivity Index) is a z-score for RU's PhD programs. The higher the $\mathrm{z}-$ score, the better. Put another way, a zscore of 0.0 would mean that the PhD Program's FSPI is equal to the mean of all $\mathrm{PhD}$ programs in the given discipline.

At RU, the questions of "what to share" and "whom to share it with" looms large. I noted earlier that the literature reports relatively few objections to being transparent (see Wehmeier and Raaz, 2012). At the same time-being transparent, especially fully transparent-does have implications. "It almost goes without saying that complete transparency is not possible-nor is it even desirable, in many cases" (p. 6) Bennis, et al. (2008). Being fully transparent, or knowing the level of transparency that might be most appropriate, is not that simple. It requires sound judgment within the context of your internal and external environment.

The examples below serve to illustrate the potential complexity of being more transparent:

- Our academic departments have always used Academic Analytics with an eye toward continuous improvement. If we begin to show national rankings especially during times of meager resources, are the departments likely to enter fierce competition, not cooperation?

- As we become more transparent, we also need more resources to education and train those using and working with the data. Do we have the human resources to provide this training? This must be a consideration when becoming more transparent.

- What are the unintended consequences of incorrect data or rankings that are incorrect? For example, what if you have an academic program that gets compared to the wrong discipline and suddenly this program looks considerably weaker. If those rankings are shared widely, particularly externally, the damage is already done. Reviewing and validating as many as forty academic programs or more at some research universities will take considerable effort.

- What if a department chair intentionally violates the vendor contract by sharing protected information? It could happen especially if the program is up for consolidation or even elimination. Who is liable? The faculty member, the institution, both parties?

- If an institution is going to share individual faculty scholarly outputs, or even an academic program's scholarly performance, it should not be done "out of context." Teaching performance; service to students, the discipline and/or profession, the university, the state; as well as contributions to economic development must also be shared. Furthermore, the goals of the academic program or department 
should be carefully considered. Point being, scholarly productivity data should probably not be shared in isolation because it has the potential to lead individuals to the incorrect conclusions.

- In the best interest of institution, how do you know what level of transparency is optimal or best given the situation and the context?

\section{Principles of Transparency: Some Ex- amples}

If an institution is choosing to be more transparent, it is not likely to be as simple as "switching a light on." As noted earlier, it requires judgment, an understanding of context, and careful consideration of the unintended consequences. In addition, I would argue that if institutions could develop a set of principles to guide their actions, it would help considerably. In this spirit, noted below are suggested principles that might be applied at Rivers University. Although I used Academic Analytics as the example in this paper, the principles I have outlined below are intended to be applied more universally, to a wider range of data transparency situations within a university.

\section{Principles of Good Practice in (Data)}

\section{Transparency include:}

1. Following federal and state laws and regulations, as well as university policy and procedures. Honors vendor contract.

2. Seeking input from those directly involved (e.g., faculty, chairs, deans, etc.) prior distribution

3. Determining whether the recipient has a "managerial right to know"

4. Placing a premium on data accuracy and fair representation
5. Providing a means for units to respond and react first

6. Carefully considering recipient competencies to understand the information and adjusting what is delivered accordingly

7. Evaluating and preparing for the potential unintended consequences prior to distribution

8. Carefully considering the goal(s) (e.g., formative evaluation, summative evaluation, etc.) for sharing the data and ensuring "what are provided to whom" is consistent with this goal(s)

\section{Conclusions}

By all indications, practicing "measured or tempered transparency" has a tremendous number of benefits to the institution and its constituencies. By measured or tempered, I mean that we intentionally and consciously consider the implications of what may be shared, and then adjust what is delivered accordingly. We also need to find better ways to help us decide how best to share data and information for the common good of the institution. Thus, I believe that if we can outline universal principles that can serve as a foundation on our campus, tweak them accordingly given the context, it will go a long way to serving our needs and building trust through tempered, transparent actions and exchanges.

\section{References}

Beatele, G. \& Seidenglanz, R. (2008). Trust and credibility: Prerequisites for communication management. In: Zerfass A., van Ruler, B. and Sriramesh, K. (eds) Public 
Relations Research: European and International Perspectives and Innovations. Wiesbaden (Germany): V.S. Verlag, 49-55.

Bennis W, Goleman, D., \& O'Toole, J. (2008). Transparency: How leaders create a culture of candor. San Francisco: Jossey-Bass.

Nicolaou, A.I. (2010). Integrated information systems and transparency in business reporting. International Journal of Disclosure and Governance, 7:3, 216-226.

Noveck, B. (2013). Open government initiative discussion phase: Transparency principles. Retrieved on June 10, 2013, from
http://www.whitehouse.gov/blog/Discussion-Phanse-Transparency-Principles.

Transparency International. (2013). Transparency and data initiative. Retrieved on June 10, 2013, from http://www.transparencyinitiative.org/about/definitions.

Wehmeier, S. \& Raaz, O. (2012). Transparency matters: The concept of organizational transparency in the academic discourse. Public Relations Inquiry, 3, 337366. 